\title{
Using the medicine ball throw test to predict upper limb muscle power: validity evidence
}

\section{Teste do arremesso de bola medicinal para predizer potência muscular de membros superiores: evidências de validade}

\section{Marco Aurélio Ferreira de Jesus Leite ${ }^{1}$ (D) https://orcid.org/0000-0002-8332-5075 Jeffer Eidi Sasaki² \\ (D) https://orcid.org/0000-0002-2083-4104 \\ Camilo Luis Monteiro Lourenço ${ }^{3}$ \\ (D) https://orcid.org/0000-0003-0231-1702 \\ Hugo Ribeiro Zanetti ${ }^{4}$ \\ (D) https://orcid.org/0000-0002-2852-3634 \\ Gustavo Ribeiro da Mota² \\ (D) https://orcid.org/0000-0002-6109-0658 \\ Edmar Lacerda Mendes ${ }^{2}$ \\ (iD) https://orcid.org/0000-0001-8182-8296}

Abstract - Muscle power is the product of muscle force and velocity, which translates into the ability to produce force in a short time interval. Periodic evaluations of strength and power, coupled with training strategies for these capacities, are of great value to athletes and multi-sports coaches, since they are key determinants for team success. Specifically, in rugby, where passing is a predominant and determinant element of sporting success, few field tests are available for assessing upper limb muscle power. The purpose of this point of view is to correct the upper limb power prediction equation previously published by our group and to highlight its concepts and applicability in sports, especially in rugby.

Key words: Athletic performance; Sports; Muscle strength; Reproducibility of results.

Resumo - Potência muscular é o produto entre força e velocidade, que se traduz na capacidade de produzir força em um curto intervalo de tempo. Avaliaçôes periódicas de força e potência, combinadas a estratégias de treinamento para essas capacidades, são de grande valor para atletas e treinadores multi-esportivos, pois são determinantes para o sucesso da equipe. Especificamente no rugby, onde opasse é elemento predominante e determinante do sucesso esportivo, poucos testes de campo estão disponiveis para avaliar força muscular de membro superior. O objetivo deste ponto de vista é corrigir a equação de predição de potência do membro superior previamente publicada pelo nosso grupo e destacar seus conceitos e aplicabilidade nos esportes, especialmente no rugby.

Palavras-chave: Desempenho atlético; Esportes; Força muscular; Reprodutibilidade dos testes.
1 Universidade Federal do Triângulo Mineiro. Programa de Pós-Graduação em Ciências Fisiológicas. Uberaba, MG. Brasil.

2 Universidade Federal do Triângulo Mineiro. Programa de Pós-Graduação em Educação Física. Uberaba, MG. Brasil.

3 Universidade Federal de Santa Catarina. Florianópolis, SC. Brasil.

4 Centro Universitário IMEPAC. Araguari/MG. Brasil

Received: 23 April 2019 Accepted: 15 July 2019

How to cite this article De Jesus-Leite MAF, Sasaki JE, Lourenço CLM, Zanetti HR, Mota GR, Mendes EL. Rev Bras Cineantropom Desempenho Hum 2020, 22:e63286. DOl: http://dx.doi. org/10.5007/1980-0037.2020v22e63286

Copyright: This work is licensed under a Creative Commons Attribution 4.0 International License. 


\section{INTRODUCTION}

Sport coaches are usually interested in increasing and optimizing the performance of their athletes using precise and efficient strategies. In high performance sports, strength and power represent essential physical abilities and are determinants for team success in various modalities, such as track and field, combat sports, American football, basketball, rugby, among others. The generation of muscle power, independent of the sport modality, is important for different sports gestures, like sprints, changes of direction, kicks, blows, launches, jumps and passes.

In rugby, as in other contact sports, athletes need to perform a variety of high intensity motor actions ${ }^{1}$. Thus, muscle power stands out as the primary physical capacity in motor gestures during a rugby game ${ }^{2}$. Although many studies focus on strategies for increasing lower limb muscle power ${ }^{3}$, we highlight the need to specifically optimize muscle power of upper limbs (PUL) in rugby. Rugby players on average perform 106 passes per game ${ }^{4}$, up to $50 \%$ of which are long distance ${ }^{5}$ with the objective of, at a given moment, create numerical advantage in the attack ${ }^{2}$.

The development and maintenance of muscular strength is fundamental during the sports season ${ }^{6}$. Thus, its periodic evaluation is necessary for the prescription of optimal loads for training muscle power ${ }^{3,6,7}$. The training planning for high-performance athletes should consider that the development of muscle power lies on the application of force at high speeds and that, for most sports, what really matters is not the maximum strength, but rather the rate of force development applied within the sporting gesture. The lack of resources for the acquisition of devices and inertial sensors for power evaluation and identification of optimal loads constitutes one of the main limitations in amateur teams ${ }^{8}$.

Recently, we proposed a low-cost strategy for indirect determination of PUL in rugby athletes?. More specifically, we developed and validated a regression equation for predicting PUL in rugby athletes from the medicine ball throw test (MBT). This equation has great applicability in the sporting context, as it may serve to monitor training progress in rugby, as well as in other modalities in which PUL is preponderant. However, in the original article ${ }^{9}$, the predictive equation was published with errors, precluding the accurate prediction of PUL based on MBT. In this Point of View, we would like to reinforce the validation process of our predictive model and to carry out the correction of our previously published equation.

\section{VALIDITY EVIDENCE AND CORRECTION OF THE PREDICTION EQUATION}

In novice athletes, strength training results in the increased ability to produce force by improving the relation of activation and inhibition of agonist and antagonist muscles. On the other hand, in experienced athletes, strength training alone may be insufficient to improve muscle power, thus 
demanding more specificity in the training process. Therefore, power training should be as specific as possible regarding the sporting gesture. The working muscles must be the same as those used in the sport modality, and even the resistance of the exercise must resemble that of the motor action of interest ${ }^{10}$, optimizing the skill transfer to the actual sport.

Considering all theoretical conclusions, we verified the agreement and prediction of PUL from the distance in the MBT in rugby players ${ }^{9}$. The experimental design included the following steps: 1) measurement of maximum strength (1RM) in the bench press (horizontal push); 2) MBT performed after $48 \mathrm{~h}$ of the bench press; and 3) Direct PUL measurement using a Myotest ${ }^{\circledR}$ triaxial accelerometer (model S4P, Sion, Switzerland) coupled to a guided barbell during the bench press exercise, which was performed $48 \mathrm{~h}$ post MBT. Loads corresponding to 30\%, 40\%, 50\% and $60 \%$ of the $1 \mathrm{RM}$ test were used for the PUL test. Each participant performed three consecutive repetitions for each intensity. All protocols were based on tests validated in the literature.

The initial results indicated a positive and strong correlation between PUL at $30 \%, 40 \%$ and $50 \%$ of $1 \mathrm{RM}$ and the distance in the MBT. This allowed us to develop a regression equation to predict PUL from MBT. The intensity of $60 \%$ of $1 \mathrm{RM}$ presented lower PUL value in relation to $40 \%$ and $50 \%$ of $1 \mathrm{RM}$, yet no difference in relation to $30 \%$ of $1 \mathrm{RM}$. On the other hand, there were no differences between PUL when using 30\%, $40 \%$ and $50 \%$ of $1 \mathrm{RM}$, which possibly denotes that real maximum power was achieved between $30-50 \%$ of $1 \mathrm{RM}$ in our sample. In our study, we also observed that sex (male or female) was related to differences in MBT distance. Thus, this variable was also considered a predictor variable for PUL.

Based on the abovementioned observations, we used a linear regression to verify the associations of MBT, sex, and PUL $\left(r^{2}=0.776, p<0.01\right)$. This allowed us to develop a PUL prediction equation, which uses MBT distance and sex as predicting variables. This equation was applied to MBT distance from all participants and their predicted PUL values were compared with the criterion test (Myotest). This comparison indicated no significant differences between PUL measured by the Myostest accelerometer and PUL predicted by our equation $(\mathrm{p}<0.05)$. To verify the dispersion of predicted values, a residual analysis was performed, which verified a residual error of approximately $\pm 99.5 \mathrm{~W}$. The Bland-Altman method was then used to identify the prediction bias $(-0.001 \mathrm{~W})$ with its corresponding upper and lower limits of agreement ( 256.64 and $-256.64 \mathrm{~W}$, respectively, at 95\% CI). The Bland-Altman was also applied to verify prediction bias when PUL values were adjusted for fat free mass. In this case, prediction bias for PUL was $0.06 \mathrm{~W} / \mathrm{kg}$ of lean mass, with upper and lower limits of agreement (95\%) of 3.58 and $-3.69 \mathrm{~W} / \mathrm{kg}$ of lean mass.

We observed low bias in the application of the equation by sex, absolute mass and fat free mass adjustments. For reliability testing, an inter-class coefficent (ICC) test was also performed. The ICC test indicated that PUL predicted by the equation presented high reliability among individuals 
(CCI: $0.861 ; \mathrm{p}<0.01$ ) for power in the different percentages of $1 \mathrm{RM}$. It is important to highlight that we used the leave-one-out method to verify the model performance in terms of accuracy and precision. By adopting this method of cross validation, the accuracy of the proposed equation is tested in a theoretically independent sample, making it possible to estimate the true performance of the equation.

We have recently observed that researchers and scholars have begun to use our PUL prediction equation. Some of these researchers have reported that the PUL values predicted by our equation were much higher than what would be expected. We, therefore, rechecked the equation ${ }^{9}$ and verified that the latter was published with some errors in its second and third terms (see below). These errors render PUL values that are not feasible. Therefore, we would like to take this opportunity to make the appropriate corrections. Below we present the previously published ${ }^{9}$ incorrect equation and the corrected version.

Incorrect equation published in Leite et al. ${ }^{9}$ PUL $($ Watts $)=-17.897+(182.025$ * MBT $)+(1134.563$ * sex $)$

$$
\begin{gathered}
\text { Correct equation: } \\
\text { PUL }(\text { Watts })=-17.897+(182.055 \text { * MBT })+(-134.563 \text { * sex })
\end{gathered}
$$

Where: $\mathrm{PUL}=$ power of the upper limbs; MBT = medicine ball throw distance in meters; Sex, male $=1 ;$ female $=2$

We hope that this corrected equation can serve as a tool for assessing PUL in male and female rugby players as well as in other modalities in which PUL is key to high levels of sport performance. In this sense, the equation has high feasibility for field use by coaches and physical trainers for determinations of PUL of their athletes.

\section{COMPLIANCE WITH ETHICAL STANDARDS}

\section{Funding}

This research did not receive any specific grant from funding agencies in the public, commercial, or not-for-profit sectors. This study was funded by the authors.

\section{Ethical approval}

Ethical approval was obtained from the local Human Research Ethics Committee - University Federal do Triângulo Mineiro and the protocol (no. 2382/2012) was written in accordance with the standards set by the Declaration of Helsinki.

\section{Conflict of interest statement}

The authors have no conflict of interests to declare.

\section{Author Contributions}

Conceived and designed the experiments: MAFJL and ELM Performed 
the experiments: MAFJL and ELM. Analyzed the data: MAFJL; JES; CLML; HRZ; GRM and ELM. Contributed reagents/materials/analysis tools: MAFJL; JES; CLML; HRZ; GRM and ELM. Wrote the paper: MAFJL; JES; CLML; HRZ; GRM and ELM.

\section{REFERENCES}

1. Johnston RD, Gabbett TJ, Jenkins DG. Applied sport science of rugby league. Sports Med Auckl NZ 2014;44(8):1087-100.

2. Bevan HR, Cunningham DJ, Tooley EP, Owen NJ, Cook CJ, Kilduff LP. Influence of postactivation potentiation on sprinting performance in professional rugby players. J Strength Cond Res Natl Strength Cond Assoc 2010;24(3):701-5.

3. Loturco I, Pereira LA, Zanetti V, Kitamura K, Abad CCC, Kobal R, et al. Mechanical Differences between Barbell and Body Optimum Power Loads in the Jump Squat Exercise. J Hum Kinet 2016;54:153-62.

4. Biscombe T, Drewett P. Rugby: steps to sucess. 2a edição. Canadá: Human Kinetics; 2010. 240 p.

5. Vaz L, Rooyen MV, Sampaio J. Rugby Game-Related Statistics that Discriminate Between Winning and Losing Teams in Irb and Super Twelve Close Games. J Sports Sci Med 2010;9(1):51-5.

6. Cormie $\mathrm{P}, \mathrm{McGuigan} \mathrm{MR}$, Newton RU. Developing maximal neuromuscular power: part 2 - training considerations for improving maximal power production. Sports Med Auckl NZ 2011;41(2):125-46.

7. Leite MAF de J, Guedes JM, Angelotti LCZ, Motta G da R, Mendes EL. Análise do pico de potência de membro superior em jogadores amadores de rugby. Conexões 2015;13(2):1-14.

8. Camomilla V, Bergamini E, Fantozzi S, Vannozzi G. Trends Supporting the In-Field Use of Wearable Inertial Sensors for Sport Performance Evaluation: A Systematic Review. Sensors 2018;18(3):873.

9. Leite MAF, Sasaki JE, Lourenço CLM, Zanetti HR, Cruz LG, Mota GR, et al. Medicine ball throw test predicts arm power in rugby sevens players. Rev Bras Cineantropom Desempenho Hum 2016;18(2):166-76.

10. Zatsiorsky VM, Kraemer WJ. Ciência e prática do treinamento de força. Phorte; 2008. $254 \mathrm{p}$.

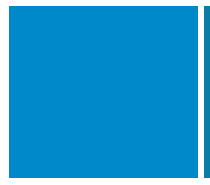

Corresponding author

Marco Aurélio F. Jesus-Leite

Pós-graduação em Ciências Fisiológicas - Universidade Federal do Triângulo Mineiro

E-mail:marcoleite@unicerp.edu.br

marcoferreiraleite@hotmail.com 